\title{
Compliance of randomised controlled trials in trauma surgery with the consort statement: a systematic review
}

\author{
Seon-Young Lee ${ }^{1 *}$, Penelope Teoh ${ }^{1}$, Christian Camm ${ }^{2,3}$, Riaz Agha ${ }^{1}$ \\ From 2nd Clinical Trials Methodology Conference: Methodology Matters \\ Edinburgh, UK. 18-19 November 2013
}

\section{Introduction}

Randomized controlled trials (RCTs) are the criterion standard for assessing new interventions. However bias can result from poor reporting which also makes critical appraisal and systematic review challenging. The CONSORT criteria for non-pharmacological trials (CONSORT NPT) published in 2008 provided a set of 23 mandatory items that should be reported in an RCT. This is the first study to assess the compliance of RCTs in Trauma with CONSORT NPT criteria.

\section{Method}

The Medline database was searched using the MeSH term "wounds and injuries" for English language papers published between January 2009 and December 2011. Relevant papers were scored by two reviewers and compared against surrogate markers of paper quality (such as journal impact factor).

\section{Results}

83 papers were deemed suitable for inclusion. The mean CONSORT score was $11.2 / 23$ items (48.5\%, range 3.3818.17). Compliance was poorest for items relating to the adherence of care providers $(0 \%)$, abstract $(4.8 \%)$ and implementation of randomisation (6.0\%). There was a significant correlation between the CONSORT Score and the Impact Factor of the publishing journal ( $\mathrm{rho}=0.37$, $\mathrm{p}=0.0006$ ) but not for the number of patients or authorsor single vs multi-centre trials.

\section{Conclusion}

The reporting quality of RCTs in Trauma surgery needs improvement. We suggest ways this could be improved

${ }^{1}$ Faculty of Medicine, University of Southampton, Southampton, UK Full list of author information is available at the end of the article including; better education, awareness and a cohesive strategy amongst all stakeholders and the hard-wiring of compliance through electronic journal submission systems.

\section{Authors' details}

'Faculty of Medicine, University of Southampton, Southampton, UK. ${ }^{2}$ New College, University of Oxford, Oxford, UK. ${ }^{3}$ Department of Plastic Surgery, Stoke Madeville Hospital, Aylesbury, UK.

Published: 29 November 2013

doi:10.1186/1745-6215-14-S1-P121

Cite this article as: Lee et al.: Compliance of randomised controlled trials in trauma surgery with the consort statement: a systematic review. Trials 2013 14(Suppl 1):P121.

\section{Submit your next manuscript to BioMed Central and take full advantage of: \\ - Convenient online submission \\ - Thorough peer review \\ - No space constraints or color figure charges \\ - Immediate publication on acceptance \\ - Inclusion in PubMed, CAS, Scopus and Google Scholar \\ - Research which is freely available for redistribution

